\title{
Comparative Studies of the Phytochemical, Antioxidant and Antimicrobial Properties of Cashew Leaf, Bark and Fruits Extracts
}

\author{
John O. Onuh*, Gabriel Idoko, Peter Yusufu, Felicia Onuh \\ Department of Food, Nutrition \& Home Sciences, Kogi State University, Anyigba, Kogi State, Nigeria \\ *Corresponding author: onuh.jo@ksu.edu.ng
}

\begin{abstract}
Extracts of the leaf, stem bark and fruit of cashew plants were investigated to determine their phytochemical, antioxidant and antimicrobial properties. Cashew leaves, stem barks and fruits of the Brazilian Jumbo variety were processed, extracted and analyzed for their phytochemical, antioxidant and antimicrobial activities. The results showed that the phytochemical contents varied significantly between the sample extracts. Carotenoids content of cashew extracts are 88.86, 125.93 and $100.33 \mathrm{mg} / \mathrm{g}$ for the leaf, bark and fruit respectively. The stem bark extract showed significantly highest tannin content $(2.01 \mathrm{mg} / \mathrm{g})$ compared to the cashew fruit extract $(1.56 \mathrm{mg} / \mathrm{g})$ and cashew leaf extract $(1.19 \mathrm{mg} / \mathrm{g})$. Total phenolic content of the cashew plant parts varied significantly from $103.92-983.23 \mathrm{mg} / \mathrm{g}$ sample of the extract with the leaf extract having significantly lowest value while the fruit had the highest value. Cashew fruit extract exhibited significantly highest percentage DPPH scavenging activity at all concentrations. There was a positive correlation between the total phenolic content and antioxidant activities of cashew extracts suggesting that the phenolic content may directly influence the antioxidant activities. Extracts of cashew leaves and stem barks exhibited appreciable inhibition on all human pathogens screened compared to the fruit extract which was only active against salmonella typhi. Cashew extracts could therefore be used as a potential source of ingredients in the development of nutraceuticals and functional foods for the control, management and treatment of health disorders.
\end{abstract}

Keywords: cashew, extracts, antioxidant, phytochemical, functional foods, antimicrobial

Cite This Article: John O. Onuh, Gabriel Idoko, Peter Yusufu, and Felicia Onuh, "Comparative Studies of the Phytochemical, Antioxidant and Antimicrobial Properties of Cashew Leaf, Bark and Fruits Extracts." American Journal of Food and Nutrition, vol. 5, no. 4 (2017): 115-120. doi: 10.12691/ajfn-5-4-1.

\section{Introduction}

Plants have a wide variety of medicinal potentials that has remained greatly untapped. This has generated huge and renewed interest in ethnomedicine, ethnobotany and ethnopharmacology [1]. Extracts from these plant parts (especially the roots, stems, leaves and fruits) have been used extensively to treat infectious diseases and inflammatory and oxidative stress related conditions $[2,3,4]$. Traditional medicinal plants have the ability to synthesize a wide variety of chemical compounds that play a major role in primary health care as therapeutic remedies. Additionally, they serve as alternative sources for western medicines that are expensive, synthetic and as consequence, may have adverse side effects [2,5]. Chemical compounds in plants mediate their effects on the human body through processes identical to those in conventional drugs [2].

The cashew tree (Anacardium occidentale $\mathrm{L}$ ) is one such plant with potentials for use as a medicinal plant. It belongs to the family of the flowering plant, Anacardiaceae, whose leaves and/or the stem barks have been used for treatment of eczema, diarrhea, dysentery, colonic pains, genital problems, venereal diseases, impotence, bronchitis, cough and syphilis-related skin disorders [6,7]. It has also been reported to possess anti-diabetic, anti-inflammatory anti-microbial and anti-ulcerogenic properties [8]. These bioactivities may be attributed to the presence of secondary metabolites (including flavonoids, phenols, phenolic glycosides, saponins and glycosides) on the plant $[9,10]$. These compounds however, differ widely in their structure, biological activities and mechanisms of actions, and consequently may modulate different pathways.

Many researchers have reported that medicinal plants contain various bioactive components that exhibits antioxidant and anti-microbial activities with beneficial health effects $[9,11,12,13]$. Oxidative stress has been implicated in the development of chronic and degenerative ailments such as cancer, autoimmune disorders, rheumatoid arthritis, cataract, aging, cardiovascular and neurodegenerative diseases $[9,14,15]$. Antioxidants are chemical compounds that reacts with and neutralize free radicals generated in biological systems during cellular metabolism, thus preventing them from causing damage [12]. Natural antioxidants are however gaining desired attention for their ability to protect the human body from these free radicals mediated oxidative stress reactions [9,14]. 
Antioxidants mediate these reactions by free radical scavenging, peroxide decomposition, suppression of singlet oxygen, enzymatic inhibition and increasing the levels of endogenous defences [16,17].

The medicinal and antimicrobial properties of cashew plant and their component phytochemicals (alkaloids, tannins, flavonoids, phenolics and other compounds) have been investigated [18,19,20]. Ajibesin et al. [20] reported that flavonoids and tannins are responsible for the antimicrobial activity of cashew stem against syphilis. This is probably attributed to their ability to form complexes with extracellular and soluble proteins and also with bacterial cell walls resulting in microbial membranes disruptions and inhibitory actions [19,21]. Phenolic compounds are also believed to be toxic to microorganisms by the mechanism of enzyme inhibition by the oxidized compounds, possibly through reaction with sulfhydryl groups or through more non-specific interactions with the proteins [19].

Chemical compositions and biological activities of a plant have been found to be affected by seasonal variation, state of maturity and location among other factors. Although various studies have been carried out on the phytochemical constituents in many medicinal plants and especially in cashew plants, not much attention has been paid to the variation in the phytochemicals that appear in the different parts of these plants. Therefore, the objective of this study was to determine the phytochemical, antioxidant and antimicrobial properties of cashew leaf, bark and fruit extracts. This will contribute to the knowledge base on the application of these extracts as ingredients in developing nutraceuticals and functional foods for the amelioration, management and potential treatment of chronic health conditions.

\section{Materials and Method}

\subsection{Materials}

Cashew leaves, stem barks and fruits of the Brazilian Jumbo variety used for this study were obtained from The Cocoa Research Institute of Nigeria (CRIN) Experimental Station in Ochaja, Kogi State, Nigeria. The samples were transported to the Food, Nutrition and Home Sciences laboratory for processing and sample extraction and analyses. All analytical grade reagents were obtained from the Food Chemistry Laboratory of the Kogi State University, Anyigba - Nigeria. Culture media, peptone water, and microorganisms screened (Gram +ve bacteria Staphylococcus aureus and Bacilllus cereus, Gram -ve bacteria - E. coli, Streptococcus mutans, Salmonella typhi and fungi - Candida albicans ) were obtained from the Microbiology laboratory of the Kogi State University University, Anyigba - Nigeria.

\subsection{Preparation of Extracts}

Fresh leaves and bark of the cashew collected were pounded to increase surface area and extracted by soaking in methanol according to the method of Varghese et al. [21]. The extracts were filtered through Whatman No. 1 filter paper, concentrated using rotary evaporator, dried and stored at $-20^{\circ} \mathrm{C}$ in a deep freezer. However, for the fruit extracts, fresh ripe fruits of cashew apple were rinsed thoroughly with distilled water and the nut separated from the succulent apple. The succulent portion was pasteurized at $85^{\circ} \mathrm{C}$ for 2 mins and mashed physically for juice extraction. The cashew juice (fruit extract) was transferred to a sterile bottle, corked and stored under refrigeration until required for analyses.

\subsection{Sample Analyses}

\subsubsection{Quantitative Determination of Phytochemicals}

The alkaloid content of mango peel flour samples was determined according to the modified method of Harbone [22] on a $0.5 \mathrm{~g}$ sample dissolved in $96 \%$ ethanol: $20 \%$ $\mathrm{H}_{2} \mathrm{SO}_{4}$. The aluminium chloride colorimetric method was used for the determination of the flavonoid content of mango peel samples according to the procedure reported by Woisky and Salatino [23]. The method of Burns et al. [24] was adopted for the determination of the saponin content of mango peel samples. Tannin content of mango peel samples was determined using the AOAC [25] method on a $0.2 \mathrm{~g}$ sample. Carotenoids content was determined using the method described by RodriguezAmaya [26]. 2g of the sample were mixed with $50 \mathrm{ml}$ of acetone until loss of pigmentation. The mixture was filtered and total carotenoids was extracted using $100 \mathrm{ml}$ of petroleum ether. Absorbance of the extracted fraction was then read at $450 \mathrm{~nm}$ by using UV spectrophotometer. Total carotenoid content was then estimated using a calibration curve of beta-carotene $(1 \mathrm{mg} / \mathrm{ml})$ as standard.

\subsubsection{Antioxidant Activity}

\subsubsection{Total Phenolic Determination}

The concentration of phenols in the mango peel was determined using the Folin-Ciocalteu colorimetric method as described by Grussu et al [27] with $1000 \mu \mathrm{M}$ solution of catechin as the standard. An aliquot of standard, blank, or the extract (up to $100 \mu \mathrm{l}$ ) will be added to $1000 \mu \mathrm{l}$ of the Folin-Ciocalteu reagent (Sigma Chemical Company, St. Louis, MO), which has been diluted previously 1:9 with water. The solution will be allowed to stand at $20-25^{\circ} \mathrm{C}$ for 20 min before colorimetric measurement at $750 \mathrm{~nm}$.

\subsubsection{Determination of DPPH Scavenging Activity}

The in vitro antioxidant activities of mango peels samples were measured on the basis of the scavenging activity against 1,1 - diphenyl 2 - picrylhydrazyl (DPPH) radical according to the method described by BrandWilliams et al [28] with slight modifications. One $\mathrm{ml}$ of $0.1 \mathrm{mM}$ DPPH solution in methanol was mixed with $1 \mathrm{ml}$ of mango peel flour sample extract solution of varying concentrations (1000, 500, 250, 125, 62.5 and 31.25 $\mu \mathrm{g} / \mathrm{ml})$. Corresponding blank was prepared and L-ascorbic acid $(1-100 \mu \mathrm{g} / \mathrm{ml})$ was used as reference standard. The reaction was carried out in triplicates and decreases in absorbance were measured at $517 \mathrm{~nm}$ after 30 minutes in the dark using UV - VIS spectrophotometer. The inhibition percentages (\%) was calculated according to the given formula; 


$$
\text { Inhibition }(\%)=[(\mathrm{AB}-\mathrm{AA}) / \mathrm{AB}] \times 100
$$

where

$\mathrm{AB}=$ Absorbance of blank sample $(\mathrm{t}=0 \mathrm{~min})$

$\mathrm{AA}=$ Absorbance of tested extract solution $(\mathrm{t}=15 \mathrm{~min})$.

\subsubsection{Determination of Antimicrobial Activities}

Crude extracts from cashew leaf, stem bark and fruits were screened in vitro for antimicrobial activities according to the method of Aiswarya et al. [19]. The strains of the different microorganisms used for the investigations. Nutrient agar and peptone water were used as culture media following the manufacturers' instructions. Sterilization of Nutrient agar was done in an autoclave at $121^{\circ} \mathrm{C}$ for 15 minutes, after which they were allowed to cool to about $35-45^{\circ} \mathrm{C}$. The antimicrobial sensitivity testings of the extracts were determined using disc diffusion method according to Aiswarya et al. [19]. The nutrient Agar plates were prepared by pouring $15-20 \mathrm{ml}$ of molten media into sterile petri plates and were allowed to solidify for 5 minutes. Then $100 \mu \mathrm{l}$ of the inoculum of microorganism suspension was swabbed uniformly using sterile cotton swab and it was allowed to dry for 5 minutes. Wells, with diameter of $7 \mathrm{~mm}$, were cut on the surface of the plates and different concentrations of extracts were loaded into the wells with the help of sterile forceps. The plates were then inverted and incubated at $37^{\circ} \mathrm{C}$ for about $16-24 \mathrm{hr}$ independent on the strain been tested. After incubation, the diameters of the zones of complete inhibition were measured and recorded in millimetres (mm).

\subsection{Statistical Analysis}

Results of all determinations were expressed as means of triplicate values. Data were subjected to one-way Analysis of Variance (ANOVA) and significant differences detected using Tukey's test. An IBM SPSS Statistical package (version 20.0) was used for all statistical analyses.

\section{Results and Discussions}

Plant phytochemicals have been reported to prolong life by their protections against numerous human health and metabolic conditions. Cashew plant, being a potential source of bioactive compounds, has the ability to ameliorate various lifestyle related diseases. In the present study, leaf, stem bark and fruit extracts from cashew were analysed for their phytochemical, antioxidant and antimicrobial properties.

\subsection{Phytochemical Composition of Cashew Extracts}

Table 1 shows the content of phytochemicals that is present in leaf, bark and fruit extracts. The saponin content of the extracts of cashew leaf, stem bark and fruit significantly varied from $0.74-1.65 \mathrm{mg} / \mathrm{g}$ sample with the leaf having the lowest values while the fruit had the highest value. The cashew stem bark extract showed significantly highest tannin content $(2.01 \mathrm{mg} / \mathrm{g})$ compared to the cashew fruit extract $(1.56 \mathrm{mg} / \mathrm{g})$ and cashew leaf extract $(1.19 \mathrm{mg} / \mathrm{g})$. The flavonoid content of cashew plant followed similar trend observed for the saponin content with the leaf extract having significantly lowest value $(2.73 \mathrm{mg} / \mathrm{g})$ while the fruit had significantly highest value $(4.39 \mathrm{mg} / \mathrm{g})$. The concentration of carotenoids in the cashew plant extracts are as follow; leaf $(88.86 \mathrm{mg} / \mathrm{g})$, bark $(125.93 \mathrm{mg} / \mathrm{g})$ and fruit $(100.33 \mathrm{mg} / \mathrm{g})$. There were also significant differences in alkaloid contents of the extracts, with values ranging from $0.27-0.57 \mathrm{mg} / \mathrm{g}$, with the fruit extract having the lowest and the leaf extract having the highest content.

These results have shown the presence of appreciable levels of various phytochemicals in the extracts of the leaf, stem bark and fruit of cashew plant. The phytochemicals in plants and their products possess pharmaceutical and therapeutic values [29]. Variations in the concentrations of phytochemicals in the different parts of the cashew plant may be due to differences in levels of maturity, ripening, phytonutrient translocation and storage. The high bioactive and phytochemical content of the extracts of cashew leaf, stem bark and fruit may promote their use as antioxidant, antimicrobial, antiproliferative, antimutagenic and other health promoting properties $[9,11,12,13]$.

Table 1. Quantification of phytochemicals in cashew leaf, bark and fruit extracts $(\mathrm{mg} / \mathrm{g})$

\begin{tabular}{lccc}
\hline Phytochemical & Cashew Leaf & Cashew Bark & Cashew Fruit \\
\hline Saponin & $0.74 \pm 0.02^{\mathrm{c}}$ & $1.35 \pm 0.03^{\mathrm{b}}$ & $1.65 \pm 0.03^{\mathrm{a}}$ \\
Tannin & $1.19 \pm 0.25^{\mathrm{a}}$ & $2.01 \pm 0.02^{\mathrm{c}}$ & $1.56 \pm 0.02^{\mathrm{b}}$ \\
Flavanoid & $2.73 \pm 0.03^{\mathrm{a}}$ & $3.70 \pm 0.02^{\mathrm{b}}$ & $4.39 \pm 0.01^{\mathrm{c}}$ \\
Alkaloid & $0.57 \pm 0.06^{\mathrm{c}}$ & $0.40 \pm 0.00^{\mathrm{b}}$ & $0.27 \pm 0.06^{\mathrm{a}}$ \\
Carotenoid & $88.86 \pm 0.18^{\mathrm{a}}$ & $125.93 \pm 0.10^{\mathrm{c}}$ & $100.33 \pm 0.20^{\mathrm{b}}$ \\
\hline
\end{tabular}

Values in the same row with same superscript are not significantly different $(\mathrm{P}>0.05)$.

\subsection{Antioxidant Activity of Cashew Extracts}

\subsubsection{Total Phenolic Content of Cashew Extracts}

The total phenolic contents of cashew leaf, stem bark and fruit extracts is shown in Table 2. The total phenolic content of the cashew plant parts varied significantly from $103.92-983.23 \mathrm{mg} / \mathrm{g}$ sample of the extract with the cashew leaf extract having significantly the lowest value while the fruit had the highest value. Phenolic compounds are known to be natural sources of antioxidants as they scavenge free radicals which is a vital property responsible for their biological and pharmacological activities [9]. There was a positive correlation between the total phenolic content and antioxidant activities of cashew plant extracts suggesting that the phenolic content may directly influence the antioxidant activities [30]. Phenolic compounds have received much attention in recent years due to their capacity to inhibit lipid peroxidation and lipoxygenase in vitro. Consumption of foods rich in polyphenols have been reported to offer protection against cardiovascular diseases, cancers, and osteoporosis, neurodegenerative diseases and diabetes mellitus [31,32]. 
Table 2. Total polyphenol content of cashew leaf, bark and fruit extract

\begin{tabular}{cc}
\hline Sample & Total Polyphenol mg/g \\
\hline Cashew Leaf & $103.92 \pm 3.06^{\mathrm{a}}$ \\
Cashew bark & $251.82 \pm 3.06^{\mathrm{b}}$ \\
Cashew fruit & $983.23 \pm 4.63^{\mathrm{c}}$ \\
\hline
\end{tabular}

The values in the column with same super script are not significantly different $(\mathrm{P}>0.05)$.

\subsubsection{DPPH Radical Scavenging Activities of Cashew Extracts}

According to Sousa et al. [33], “antioxidants are substances, that when present at low concentrations in relation to oxidizable substrates, significantly delay or inhibit oxidative processes”. They play very vital roles in human health and nutrition as they help to combat the destructive effects of reactive oxygen species (ROS) [9]. The 1, 1 diphenyl-2-picryl hydrazyl radical scavenging activities (DPPH) is one of the most widely used methods for screening the antioxidant activities of mango peel extracts. DPPH is a stable free radical with a maximum absorbance at $517 \mathrm{~nm}$ in methanol that enables it to be widely used to test the reducing properties of many compounds (including natural substances) as well their ability to donate hydrogen by acting as antioxidants [15]. The results of the DPPH radical scavenging activities of cashew leaf, stem bark and fruit extracts are presented in Table 3. The cashew fruit extract exhibited significantly highest percentage DPPH scavenging activity at all concentrations. At $1000 \mu \mathrm{g} / \mathrm{g}$ sample, the DPPH radical scavenging activities were 93.23, 96.94, 99.22 and 93.80\% for the leaf, stem bark, fruit and ascorbic acid respectively. Cashew leaf, stem bark and fruit extracts exhibited antioxidant activity comparable to that of ascorbic acid as demonstrated by their ability to scavenge $\mathrm{DPPH}$ free radical. The results also showed that there were significant reductions in DPPH radical scavenging activities of the extracts as the concentrations decreases for all the sample extracts. It has been previously suggested that the antioxidant effects may be probably due to the phenolic contents considering the positive correlations between the phenolic content and DPPH radical scavenging [30]. Additionally, other phytochemicals (flavonoid, alkaloids, phenolic acid, tannin, anacardic acid and carotenoids) have equally been reported to enhance antioxidant potentials against free radicals and oxidative damage in the body $[9,10,11,34]$. There is also growing evidence suggesting that diets rich in fruits and vegetables may decrease the risk of chronic diseases owing to their high fiber and antioxidants (e.g., ascorbic acid and polyphenols) contents [35].

\subsection{Antimicrobial Potency of Cashew Plant Extracts}

The antimicrobial activities of cashew leaf, stem bark and fruit extracts against selected microorganisms are shown in Table 4. Ethanolic extracts of cashew leaves and stem barks exhibited appreciable inhibition on all human pathogens screened compared to the fruit extract which was only active against salmonella typhi. The zone inhibition of streptomycin ranged between $22.67-27.00$ $\mathrm{mm}$ on the tested organisms. There were no significant differences in the zone of inhibition of both the bark and leave extracts on E. coli, S. mutans, B. cereus, S. typhi, and C. albicans. However, there was a significant difference between the leaf $(18.60 \mathrm{~mm})$ and stem bark $(13.00 \mathrm{~mm})$ extracts in the zone of inhibition against $S$. aureus. Ability of the extracts to inhibit the growth of the test microorganisms could be as a result of bioactive substances (alkaloids, flavonoids, phenols saponins, steroids and tannins) present in the cashew plant parts extracts in their leaves [18 - 20]. The results also showed that cashew leaves and bark extracts have great potential as an effective antimicrobial agent. The fruit extracts showed zone inhibition of $10.17 \mathrm{~mm}$ on $S$. typhi but its action on other tested organisms were not apparent. Vivek et al. [36] revealed that $1 / 10$ of the original volume of cashew juice showed $26-36 \mathrm{~mm}$ and $16-17 \mathrm{~mm}$ zone of inhibition on $S$. aureus and $S$. mutans respectively. The difference could be as a result of the differences in the concentration of the fruit extract (juice) and the synergistic reactions of the various phytochemicals [36].

\section{Conclusions}

Cashew leaves, stem barks and fruits are rich in several important biologically active phyto-nutritional components. There is a great variation in bioactivities of these components among the various cashew plant parts screened. Cashew plants can therefore be used to provide low-cost nutritional and dietary supplement for low income groups. Cashew leaves and stem barks especially could also be used as a potential source of ingredients in the development of nutraceuticals and functional foods for the control, management and treatment of health disorders. The use of cashew leaf and stem bark extract will have the added advantage of promoting value addition, reduce waste generation, environmental pollution as well as reduced cost arising from waste disposal.

Table 3. DPPH radical scavenging property of cashew leaf, bark and fruit extracts

\begin{tabular}{|c|c|c|c|c|}
\hline \multirow[t]{2}{*}{ Concentration $\mu \mathrm{g} / \mathrm{g}$} & \multicolumn{4}{|c|}{ \% Scavenging Activity } \\
\hline & Cashew Leaf & Cashew Bark & Cashew Fruit & Ascorbic acid \\
\hline 1000 & $93.23 \pm 0.17^{\mathrm{a}}$ & $96.94 \pm 0.17^{\mathrm{b}}$ & $99.22 \pm 0.11^{\mathrm{c}}$ & $93.80 \pm 0.70^{\mathrm{a}}$ \\
\hline 500 & $92.97 \pm 0.22^{\mathrm{a}}$ & $95.42 \pm 0.12^{\mathrm{b}}$ & $99.00 \pm 0.11^{\mathrm{c}}$ & $92.10 \pm 0.78^{\mathrm{a}}$ \\
\hline 250 & $90.96 \pm 0.22^{\mathrm{b}}$ & $77.27 \pm 0.28^{\mathrm{a}}$ & $98.81 \pm 0.17^{c}$ & $91.10 \pm 0.70^{b}$ \\
\hline 125 & $81.84 \pm 0.32^{\mathrm{b}}$ & $70.13 \pm 4.20^{\mathrm{a}}$ & $98.29 \pm 0.17^{c}$ & $89.90 \pm 0.75^{c}$ \\
\hline 62.5 & $74.89 \pm 0.56^{\mathrm{b}}$ & $56.85 \pm 0.17^{\mathrm{a}}$ & $93.86 \pm 0.16^{\mathrm{c}}$ & $87.57 \pm 0.72^{c}$ \\
\hline 31.25 & $49.55 \pm 0.23^{\mathrm{b}}$ & $45.24 \pm 0.24^{\mathrm{a}}$ & $88.32 \pm 0.2^{c}$ & $84.36 \pm 0.47^{\mathrm{c}}$ \\
\hline
\end{tabular}

The values in the row with same super script are not significantly different $(\mathrm{P}>0.05)$. 
Table 4. Antimicrobial activities of ethanolic extracts of cashew leaf, bark and fruit on E. coli, S. aureus, S. mutans, B. cereus, S. typhi and C. albicans

\begin{tabular}{|c|c|c|c|c|}
\hline \multirow[t]{2}{*}{ Pathogenic organisms } & \multicolumn{4}{|c|}{ Zone of inhibition (mm) } \\
\hline & Cashew leaf & Cashew Bark & Cashew Fruit & Streptomycin \\
\hline E. coli & $15.53 \pm 1.01^{\mathrm{b}}$ & $16.50 \pm 0.50^{b}$ & $0.00 \pm 0.00^{\mathrm{a}}$ & $27.00 \pm 1.00^{c}$ \\
\hline S. aureus & $18.60 \pm 1.65^{c}$ & $13.00 \pm 1.18^{\mathrm{b}}$ & $0.00 \pm 0.00^{\mathrm{a}}$ & $22.67 \pm 0.50^{d}$ \\
\hline S. mutans & $12.76 \pm 0.65^{\mathrm{b}}$ & $15.17 \pm 1.04^{b}$ & $0.00 \pm 0.00^{\mathrm{a}}$ & $26.33 \pm 2.52^{c}$ \\
\hline B. cereus & $11.43 \pm 0.67^{\mathrm{b}}$ & $11.47 \pm 0.15^{\mathrm{b}}$ & $0.00 \pm 0.00^{\mathrm{a}}$ & $23.00 \pm 1.00^{\mathrm{c}}$ \\
\hline S. typhi & $22.83 \pm 0.76^{\mathrm{b}}$ & $23.53 \pm 0.50^{b}$ & $10.17 \pm 0.29^{\mathrm{a}}$ & $23.00 \pm 2.64^{b}$ \\
\hline C. albican & $11.00 \pm 0.89^{\mathrm{b}}$ & $10.00 \pm 1.00^{\mathrm{b}}$ & $0.00 \pm 0.00^{\mathrm{a}}$ & $27.33 \pm 2.51^{\mathrm{c}}$ \\
\hline
\end{tabular}

The values in the same rows with same super script are not significantly different $(\mathrm{P}>0.05)$.

\section{Acknowledgements}

The authors are grateful to the management of Kogi State University, Anyigba, Nigeria, for the research environment necessary to carry out this research work. We are also grateful to Dr. T. F. Emmanuel and Mr. Olusegun Olupinyo for their technical assistance in the conduct of this research study.

\section{Funding}

This research did not receive any specific grant from funding agencies in the public, commercial or not-for-profit sectors.

\section{References}

[1] Fadeyi, M. O., Adeoye, A. O. and Olowokudejo, J. D. (1989). Epidermal and phytochemical studies in the genus Boerhavia ((Nyctaginaceae) in Nigeria. International J. Crude Drug Research, 27(3), 178-184.

[2] Sokeng, D. S., Kamtchouing, P., Watcho, P., Jatsa, H. B., Moundipa, P. F., Ngounou, F. N., Lontsi, D., Bopelet, M. (2001) Hypoglycemic activity of Anacardium occidentale L. aqueous extract in normal and streptozotocin-induced diabeticrats. $J$. Diabetes Res., 36, 1-9.

[3] Olajide, O. A., Aderogba, M. A., Fiebich, B. L. (2013). Mechanisms of anti-inflammatory property of Anacardium occidentale stem bark: inhibition of NF-jB and MAPK signaling in the microglia. J. Ethnopharmacol. 145, 42-49.

[4] Olajide, O. A., Aderogba, M.A., Adedapo, A. D. A., Makinde, J.M. (2004). Effects of Anacardium occidentale stem bark extract on in vivo inflammatory models. J. Ethnopharmacol. 95, 139-142.

[5] Dhankhar, S., Ruhil, S., Balhara, M., Dhankhar, S., Chhillar, A. K. (2011). Aegle marmelos (Linn.) Correa: A potential source of Phytomedicine. J Med Plant Res., 5, 1497-1507.

[6] Bilcalho, B. (2001). Volatile compounds of cashew apple (Anacardium occidentale L.). Z. Naturforsch, 56(12), 35-39.

[7] Franca, F., Cuba, C. A., Moreira, E. A., Miguel, O., Almeida, M., das Virgens, M. L., Marsden, P. D. (1993). An evaluation of the Effectof a bark extracts from the cashew (Anacardium occidentale L.) on infection by Leishmania (Viannnia) brasiliensis. Rev. Soc. Bras. Med. Trop. 26, 151-155.

[8] Akinpelu, D. (2001). Antimicrobial activity of Anacardium occidentale bark. Fitoterapia, 72(3), 286-287.

[9] Shahidi, F., McDonald, J., Chandrasekara, A., Zhong, Y. (2008). Phytochemicals of foods, beverages and fruit vinegars: chemistry and health effects. Asia Pacific J Clin Nutr, 17, 380-382.

[10] De-Fatima, A., Modolo, L. V., Conegero, L. S., Pilli, R. A., Ferreira, C. V., Kohn, L. K et al. (2006). Lactones and their derivatives: biological activities, mechanisms of action and potential leads for drug design. Curr. Med. Chem., 13, 3371-3384.

[11] Pellati, F., Benvenuti, S., Magro, L., Melegari, M., Soragni, F. (2004). Analysis of phenolic compounds and radical scavenging activity of Echinacea spp. J. Pharm Biomed Anal, 35, 289-301.
[12] Shahidi, F. (2000). Antioxidant factors in plant foods and selected oilseeds. Bio Factors, 13, 179-185.

[13] Iwu, M. W., Duncan, A. R., Okunji, C. O. (1999). New antimicrobials of plant origin In: Perspectives on new crops and new uses, Eds. J. Janick, ASHS Press, Alexandria, VA; 457462.

[14] Willcox, J. K., Ash, S. L., Catignani, G. L. (2004). Antioxidants and prevention of chronic disease. Critical Reviews in Food Science and Nutrition, 44, 275-295.

[15] Onuh, J. O., Girgih, A. T., Aluko, R. E., \& Aliani, M. (2014). In vitro antioxidant properties of chicken skin enzymatic protein hydrolysates and membrane fractions. Food Chemistry, 150, 366-373.

[16] Bae, H. J., Jayaprakasha, G., Jifon, J., Patil, B. S. (2012). "Variation of antioxidant activity and the levels of bioactive compounds in lipophilic and hydrophilic extracts from hot pepper (Capsicum spp.) cultivars", Food Chemistry, 134(4), 1912-1918.

[17] Djuric, Z., Severson, R. K., Kato, I. (2012). "Association of dietary quercetin with reduced risk of proximal colon cancer", Nutrition and Cancer, 64(3), 351-360.

[18] Aderiye, B. I., David, O. M. and Atere, V. A. (2014). Administration of cashew extracts in the treatment of some infections and diseases. Advancement in Medicinal Plant Research, 3(3), 75-86.

[19] Aiswarya, G., Reza, K. H., Radhika, G., Mohamed, F. (2011). Study for antibacterial activity of cashew apple (Anacardium occidentale) extracts. Schol Res Lib, 3(1), 193-200.

[20] Ajibesin, K. K., Bala, D. N., Umoh, U. F. (2011). The use of medicinal plants to treat sexually transmitted disease in Nigeria: Ethnomedical survey of Niger Delta region. Int J Green Pharm, 3(5), 181-191.

[21] Varghese, J., Tumkur, V. K., Ballal, V., Bhat, G. S. (2013). Antimicrobial effect of Anacardium occidentale leaf extract against pathogens causing periodontal disease. Adv Biosci Biotechnol, 4, 15-18.

[22] Harbone, J. B. (1976). Phytochemicals methods a guide to modern technique of plant analysis. p. 1-150. London: Chapman and Hall

[23] Woisky, R. G. and Salatino, A. (1998). Analysis of propolis: some parameters and procedures for chemical quality control. J. Apicultural research, 37 (2), 95-105.

[24] Burns, J., Fraser, P. D. and Bramley, P. M. (2003). Identification and quantification of carotenoids tocopherols and chlorophyll in commonly consumed fruits and vegetables. Phytochemistry, 62, 939-947.

[25] AOAC (2010). Official Methods of Analysis. Association of Association Official Analytical Chemists, Washington DC.

[26] Rodriguez-Amaya, D. B. (2001). A guide to carotenoid analysis. ILSI, Washington DC, US, 1-71.

[27] Grussu, D., Stewart, D., McDougall, G. J. (2011). Berry polyphenols inhibit $\alpha$-amylase in vitro: Identifying active components in rowanberry and raspberry. Journal of Agricultural and Food Chemistry, 59: 2324-2331.

[28] Brand-Williams, W., Cuvelier, M., Berset, C. (1995). Use of a free radical method to evaluate antioxidant activity. LWT - Food Sci. Technology, 28, 25-30.

[29] Edeoga, H. O., Okwu, D. E and Mbaebie, B. O. (2005). Phytochemical constituents of some Nigerian medicinal plants. African Journal of Biotechnology, 4(7), 685-688.

[30] Karou, D., Dicko, M. H., Simpore, J., and Traore, A. S. (2005). Antioxidant and antibacterial activities of polyphenols from ethnomedicinal plants of Burkina Faso. African Journal of Biotechnology, 4 (8), 823-828. 
[31] Arts, C. W, Hollman, P. C. H. (2005). Polyphenols and disease risk in epidemiologic studies. Am J Clin Nutr., 81(suppl), 317S-25S.

[32] Scalbert, A., Manach, C., Morand, C., Rémésy, C., Jiménez, L. (2005). Dietary polyphenols and the prevention of diseases. Crit Rev Food Sci Nutr., 287-306.

[33] Sousa, C.M.M., Silva, H.R., Vieira Jr. G. M., Ayres, M.C.C., Costa, C.L.S., Araújo, D.S., Cavalcante, L.C.D., Barros, E.D.S., Araújo, P.B.M., Brandão, M.S. and Chaves, M.H. (2007) Fenóis Totais e Atividade Antioxidante de Cinco Plantas Medicinais. Química Nova, 30, 351-355.
[34] Johnson, I. T. (2013). Phytochemicals and health. In: Handbook of Plant Food Phytochemicals: source, stability and extraction. Ed: Tiwari, B. K., Brunton, N. P., Brennan, C. S. (2013). John Wiley \& Sons Ltd, West Sussex, UK, Pp. 49-67.

[35] World Health Organization (2003). Diet, nutrition and the prevention of chronic diseases: report of a joint WHO/FAO expert consultation.

[36] Vivek, M. N., Manasa, M., Pallavi, S., Sachidananda-Swamy, H. C. and Prashith-Kekuda, T. R. (2013). Antibacterial potential of cashew apple (Anacardium occidentale L.) Juice against clinical isolates of Staphylococcus aureus and Streptococcus mutans. Sci. Technol. Arts Res. J., 2(3), 144-146. 